\title{
ISTORIJSKI ASPEKTI RAZVOJA TRŽIŠTA KAPITALA I KOORPORATIVNOG UPRAVLJANJA
}

\section{Rezime}

Korporativno upravljanje opisuje agencijski problem koji nastaje odvajanjem vlasništva od kontrole u modemoj korporaciji i predstavlja veliki trošak za akcionare. Agencijski problem se reguliše pravnom zaštitom malih akcionara, uspostavljanjem funkcije odbora direktora kao nadzomog organa koji kontroliše menadžere i aktivnim tržištem za korporativnu kontrolu (neprijateljsko preuzimanje). Ove mehanizme reguliše regulativa hartija od vrednosti (na saveznom nivou), korporativni zakoni (na državnom nivou), i korporativni statuti, ugovome odredbe i druga pravila (na nivou firmi). Ove regulative, zakoni i odredbe zapravo defmišu raspodelu moći između akcionara i menadžera. Ovakve tehnike odbrane od preuzimanja mogu biti od koristi za akcionare, ukoliko in menadžeri koriste da bi ojačali pregovaračku moć i povećali prodajnu cenu firme. Međutim, ukoliko ih menadžeri koriste radi očuvanja sopstvenih pozicija i ostvarenje ličnih interesa, odredbe ne doprinose ostvarenju interesa akcionara

Ključne reči: korporativno upravljanje, akcijski kapital, agencijski problem, akcionari, menadžeri.

\section{UVOD}

Osnovna hipoteza ovog rada je da kvalitet sistema korporativnog upravljanja utiče na formiranje cene akcija na tržištu kapitala. Kretanje cena akcija je najvažniji pokazatelj poslovanja akcionarskih društava jer ukazuje na uspešnost i tržišno vrednovanje poslovanja korporacije. Neophodno je naglasiti da postoje faktori kretanja cena akcija koji deluju na nivou korporacije i na nivou cele privrede, dakle, faktori na koje korporacija ima uticaja i ekstemi, na koje nije moguće delovati. To je primarni razlog zbog koga je veza između kretanja cena akcija i uzroka promena cena, u nekim slučajevima jasno uočljiva, dok je u nekim veoma teško povezati faktore i odrediti pravce uticaja, bilo da se radi o ekstemim ili internim faktorima korporativnog upravljanja.

Ipak, sva istraživanja na koja se oslanja rad, su naglasila značaj kvalitetnog korporativnog upravljanja za ekonomske performanse korporacija i kotiranje akcija na tržištu kapitala. Ekonomske performanse kompanija zavise od mehanizama korporativnog upravljanja, bilo da se radi o pravnoj zaštiti akcionara, konkurentskom okruženju korporacije, strukturi vlasništva, korporativnim odredbama, odlukama donesenim na skupštinama akcionara, sastavu odbora, finansijskoj politici korporacije ili angažovanim menadžerima.

\section{KVALITET KORPORATIVNOG UPRAVLJANJA I CENA KAPITALA}

Američki istraživači Paul Gompres, Joy Ishii i Andrew Metrick ${ }^{12}$ (dalje u tekstu GIM) su, 2001. godine, pokušali da rasvetle vezu između kvaliteta korporativnog upravljanja i cene akcijskog kapitala. Njihovo istraživanje je bilo fokusirano na inteme mehanizme korporativnog upravljanja i odnos mehanizama sa pokazateljima poslovanja korporacija. Naime, oni su proučavali uticaj odredbi korporativnog upravljanja, koje su obezbeđivale odbranu od neprijateljskog preuzimanja, na prava akcionara. Koristili su 24 odredbe korporativnog upravljanja kako bi formulisali pokazatelj "Indeks upravljanja"13 (dalje u tekstu G), početkom devedesetih, i proučavali vezu između ovog Indeksa i performansi firmi u budućnosti, tokom devedesetih godina prošlog veka. Ovim istraživanjem otkrili su da postoji jaka veza između korporativnog upravljanja i prinosa po akciji.

Masovna pojava neprijateljskih preuzimanja firmi (takeover), tokom osamdesetih godina prošlog veka, doprinela je usvajanju brojnih odredbi radi odbrane od neprijateljskog preuzimanja u mnogim flrmama. ${ }^{14} \mathrm{U}$ to vreme su u SAD usvojeni novi zakoni koji su pružali firmama dodatnu zaštitu od

\footnotetext{
${ }^{10}$ Visoka škola za menadzment i ekonomiju, Kragujevac

${ }^{11}$ Beogradska poslovna škola

12 Gompers A. Paul, Joy L. Ishii, Andrevv Metrick, Corporate Governance and Equity Prices, National Bureau of Economic Research, Working Paper 8449, Cambridge, August, 2001.

13 Govemance Index ili G.

14 Prihvatanje odredbi je zapravo predstavljalo odgovor firmi na talase preuzimanja. Odredbe odbrane od neprijateljskog preuzimanja i druge korporativne odredbe koje su bile usvajane, smanjivale su prava akcionara. 
neprijateljskog preuzimanja. To je rezultiralo velikim razlikama između upravljačkih struktura američkih korporacija, što je uslovljavalo i razlike u prinosima. Pokazalo se da su korporacije, čiji su akcionari imali slabija prava, ostvarivale znatno niže prinose, imale nižu vrednost na tržištu kapitala, slabije operativne performanse, više troškove kapitala i češće su bile na udaru neprijateljskog preuzimanja.

\section{Mehanizmi korporativnog upravljanja i funkcionisanje tržišta za neprijateljsko preuzimanje}

Rezultujuće neefikasnosti su agencijski troškovi strategije disperzirane kontrole korporativnog upravljanja označeni kao troškovi kapitala disperzirane kontrole. Ovi troškovi su proporcionalno povezani sa troškovima preuzimanja. Institucije korporativnog upravljanja u firmama s disperziranom kontrolom teže da stvore uslove za efikasno funkcionisanje tržišta za neprijateljsko preuzimanje. Pri tom je važno da alokacija formalnih kontrolnih prava bude u skladu sa pravima na gotovinu (jedna akcija jedan glas). Drugi važan preduslov efikasnog tržišta za neprijateljsko preuzimanje su visoki standardi objavljivanja informacija, koji omogućavaju efikasnu procenu cena akcija i aktiviranje tržišta za neprijateljsko preuzimanje u trenutku kada potencijalni napadač uoči neefikasnosti menadžmenta i postavi ciljeve koji se mogu realizovati kroz neprijateljsko preuzimanje. Smanjenje ovih troškova kapitala je primami cilj korporativnog upravljanja. Tržište za korporativnu kontrolu je doprinelo opstanku korporacije i pored ograničenja koje nameću investicije, finansije i odluke menadžera o isplati dividendi.

Konkurentnost na tržištu proizvoda odnosno autputa korporacije direktno vodi neuspehu (bankrotstvu) firmi koje nisu u stanju da zadovolje zahteve ovog tržišta. Stoga mnoge studije, kao meru uspešnosti poslovanja korporacije, koriste rast prodaje u određenom vremenskom periodu. Osim toga, konkurencija na tržištu proizvoda je značajan faktor discipline menadžmenta koji slabo posluje, mada je vremenski okvir za ocenu delovanja ovog mehanizma veoma dug. Dakle, promocija konkurencije na tržištu proizvoda obezbeđuje rešenje na dugi rok. Uticaj ovog mehanizma u disciplini korporativnog upravljanja zavisi i od vladinih aktivnosti na unapređenju konkurentskog okruženja u zemlji, čime jačina konkurencije na tržištu proizvoda može delovati kao disciplinujući mehanizam koji smanjuje agencijske troškove.

Sposobnost otplate duga i kreditni rejting po oceni institucija koje ocenjuju poslovanje korporacija predstavlja važan signal investitorima o kvalitetu upravljanja korporacijama. Najpoznatije agencije koje pružaju ove informacije su Moodys i S\&P. Mnogi investitori se, pri ulaganju na međunarodnim tržištima kapitala, rukovode ocenama ovih agencija.

Pretnja bankrotstva Važan ekstemi mehanizam korporativnog upravljanja je stalna pretnja bankrotstva korporaciji koja predstavlja pritisak na menadžere korporacija da odgovomo posluju. Pretnja bankrotstva korporacije postoji ukoliko menadžeri izaberu pogrešnu politiku poslovanja (i u najčešćem slučaju prenesu kontrolu kreditorima) i predstavlja jedan od glavnih ekstemih mehanizama korporativnog upravljanja.

Nabrojani argumenti naglašavaju da su menadžeri, u situaciji kada su tržišta proizvoda, radne snage i preuzimanja potpuno konkurentna, svesni da optimalno poslovanje zahteva stalnu maksimizaciju vrednosti akcijskog kapitala. Dakle, konkurencija je neophodan mehanizam korporativnog upravljanja, koji funkcioniše čak i bez uplitanja vlasnika u poslovanje i nadzor kompanije. Međutim, pošto tržišta u realnom svetu nisu u potpunosti konkurentna, ne može se očekivati da samo konkurencija, kao najvažniji disciplinujući mehanizam korporativnog upravljanja, može delovati u pravcu unapređenja kvaliteta korporativne kontrole. Sistemi korporativnog upravljanja, koji predstavljaju dodatne disciplinujuće mehanizme korporativnog upravljanja, postaju relevantni kada se prihvati činjenica da agencijski problem nije jedina tržišna imperfekcija. Bez discipline na konkurentnim tržištima, agencijski problem može biti i optimalno rešen kompletnim ugovorima u kojima bi se detaljno specificirala sva prava i obaveze menadžera i vlasnika. Pošto se ovakvi ugovori u praksi ne mogu realizovati bez visokih troškova, teorijski okvir i dalje pretpostavlja postojanje imperfektnih tržišta i nekompletne ugovore.

\section{OCENJIVANJE I MERENJE KVALITETA KORPORATIVNOG UPRAVLJANJA U SREDNJOVEKOVNOJ I BALKANSKOJ REGIJI}

Istraživački radovi koji pokušavaju da rasvetle vezu između kvaliteta korporativnog upravljanja i kretanja cena akcija korporacije na tržištu kapitala, novijeg su datuma. Istraživanja uglavnom obuhvataju razvijene zemlje, mada ima pokušaja da se odrede pokazatelji kvaliteta korporativnog upravljanja za zemlje u razvoju i tranzicione privrede. Ipak, glavnu teškoću predstavlja nedostatak podataka u vidu ažuriranih informacija i nepostojanje precizne metodologije i pokazatelja za pojedine, ključne pojmove. Ekonometrijska istraživanja u ovoj oblasti postoje za SAD, Nemačku, Švajcarsku, Norvešku, Finsku, dakle, uglavnom za visoko razvijene zemlje. Među prvim pokušajima defmisanja uzročne veze između korporativnog upravljanja i cene akcijskog kapitala nalazi se istraživanje koje su, 2001. godine, uradili 
Gompres, Ishii i Metrick, istraživači sa NBER-a ${ }^{15}$ i profesori Harvardskog i Pensilvanijskog Univerziteta. Naredni pokušaj određivanja odnosa internih i ekstemih mehanizama korporativnog upravljanja i cene akcijskog kapitala u SAD, predstavlja ekonometrijsko istraživanje profesora Univerziteta iz Njujorka, Cramersa i Naira, iz aprila 2004. godine. Kao izvor podataka autori su koristili IRRC (Investor Responsibility Research Center), ${ }^{16}$ koji objavljuje detaljne listinge ovih odredbi za svaku firmu. ${ }^{17}$

Već u decembru 2004. godine Brown i Caylor, profesori državnog univerziteta iz Džordžije, formulisali su novi indeks, Gov- Score, kojim istražuju vezu između korporativnog upravljanja i performansi firmi. Na evropskom kontinentu, među prvim radovima nalazi se pokušaj norveških istraživača Bohren Oyvinda i Bemt Ame Odegarda da ocene povezanost korporativnog upravljanja i ekonomskih performansi firmi koje se kotiraju na Norveškom tržištu kapitala, krajem 2001. godine. Povezanost korporativnog upravljanja i očekivanog prinosa po akciji za Nemačku, 2003. godine, dokazali su istraživači Evropskog instituta za korporativno upravljanje ${ }^{18}$ Drobetz Wolfgang, Andreas Schillhofer i Heinz Zimmermann.

Međutim, sva ova istraživanja nailazila su na slična ograničenja. Jednim delom, problem je predstavljala činjenica da je korporativno upravljanje neistražena i nova akademska oblast sa nedovoljno razvijenom teorijskom osnovom. Drugi problem je predstavljala činjenica da je kvalitetne podatke o ovom problemu veoma teško pronaći. Stoga nije iznenađujuće da se ne može tačno odrediti koji faktori maksimiziraju vrednost sistema korporativnog upravljanja.

Korporativno upravljanje opisuje agencijski problem koji nastaje odvajanjem vlasništva od kontrole u modemoj korporaciji i predstavlja veliki trošak za akcionare. U SAD se agencijski problem reguliše pravnom zaštitom malih akcionara, uspostavljanjem funkcije odbora direktora kao nadzomog organa koji kontroliše menadžere i aktivnim tržištem za korporativnu kontrolu (neprijateljsko preuzimanje). Ove mehanizme reguliše regulativa hartija od vrednosti (na saveznom nivou), korporativni zakoni (na državnom nivou), i korporativni statuti, ugovome odredbe i druga pravila (na nivou firmi). Ove regulative, zakoni i odredbe zapravo defmišu raspodelu moći između akcionara i menadžera. Ovakve tehnike odbrane od preuzimanja mogu biti od koristi za akcionare, ukoliko in menadžeri koriste da bi ojačali pregovaračku moć i povećali prodajnu cenu firme. Međutim, ukoliko ih menadžeri koriste radi očuvanja sopstvenih pozicija i ostvarenje ličnih interesa, odredbe ne doprinose ostvarenju interesa akcionara. GIM analiza predstavlja komplementami pristup sa prethodnim istraživanjima u ovoj oblasti. ${ }^{19} \mathrm{GIM}$ se fokusiraju na vezu između velikog broja odredbi korporativnog upravljanja, koje su interno određene, i dugoročnih performansi firme. Njihove analize su urađene na osnovu literature koja ispituje uticaj nacionalnog zakona na vrednost i performanse firmi. ${ }^{20}$

Strukture upravljanja u korporaciji nisu egzogene veličine, tako da je u mnogim slučajevima teško izvući uzročne zaključke. Iz tog razloga, GIM nisu postavili zahtev o pravcu uzročnosti između korporativnog upravljanja i performansi poslovanja. Korporativno upravljanje je varijabla koja može objasniti varijacije u performansama poslovanja koje nisu već ugrađene u tržišnu cenu firme ili druge pokazatelje poslovanja.

Korelacije Indeksa upravljanja sa prinosima, vrednošću firme i agencijskim troškovima mogu biti objašnjene na nekoliko načina.

\footnotetext{
15 National Bureau of Economic Research - National Bureau of Economic Research, Više informacija na adresi: http://www.nber.org

16 Više informacija o IRRC na adresi: http://www.irrc.org/.

Investor Responsibility Research Center (IRRC) je neprofitna institucija koja se bavi istraživanjem oblasti korporativnog upravljanja i akcionarstva. IRRC podaci su dostupni samo u štampanoj formi u publikaciji "Corporate Takeover Defenses." Podaci su dobijeni iz različitih javnih izvora uključujući korporativne statute ili uredbe, izjave o zastupanju, godišnje izveštaje, kao i dokumentovane fajlove SEC. Za većinu analiza kombinovali su podatke IRRC i Center for Research in Security Price (CRSP) i S\&P kompjutersku bazu podataka. Međutim, IRRC ne ažurira podatke za svaku kompaniju u svakom novom izdanju publikacije, tako da neke promene nedostaju. Osim toga, odredbe i statuti nekih kompanija nisu bili uvek dostupni.

18 ECGI - European Corporate Govemance Institute, Više informacija na adresi: http://www.ecgi.org/

19 Veliki broj studija je istraživo direktan uticaj ovih promena na bogatstvo akcionara. Ipak, sve studije su se susretale sa teškoćama usled prihvatanja određenih odredbi koje su menjale strukturu upravljanja, jer su menadžeri dobijali veća ovlašćenja prihvatanjem odredbi. Nekoliko studija je otkrilo značajno povećanje agencijskih troškova usled prihvatanja odredbi odbrane od neprijateljskog preuzimanja i usvajanja državnih zakona o neprijateljskom preuzimanju. Borokhovich, Brunarski i Parrino su (1997) pokazali da su plate CEO porasle u firmama koje su prihvatile odredbe o odbrani od neprijateljskog preuzimanja. Bertrand $\mathrm{i}$ Mullainathan (1999 i 2000) su otkrili slične rezultate za CEO i ostale zaposlene u firmama, nakon usvajanja novih državnh zakona o preuzimanju. Takođe su otkrili da su ove promene uticale na smanjenje ukupne produktivnosti faktora proizvodnje i prinosa na kapital. Garvey i Hanka (1999) su pokazali da državni zakon o preuzimanju uzrokuje promenu leveridža koji povećava slabost korporacije. Comment i Schvvert (1995) koji su otkrili da ovi zakoni zapravo ne sprečavaju neprijateljsko preuzimanje.

20 La Porta R., Lopez-de-Silanes F., Shleifer A., i R. Vishny, "Investor Protection and Corporate Govemance," Journal of Financial Economics 58, str. 3-28, 2000. i La Porta R., Lopez-de-Silanes F., Shleifer A., i R. Vishny, Investor Protection and Corporate Valuation, Harvard University, Working Paper, 2001.
} 
Jedno objašnjenje, koje su dali rezultati studija, ukazuje da odredbe korporativnog upravljanja koje smanjuju prava akcionara direktno stvaraju dodatne trškove akcionarima. Ukoliko tržište potcenjuje ove dodatne troškove, tada prinos na akcije može biti manji nego što je očekivano i vrednost firme bi na početku perioda posmatranja mogla biti suviše visoka. Veći agencijski troškovi bi takođe mogli da ukažu na niže operativne performanse poslovanja.

Altemativno objašnjenje je da menadžeri razumeju da će buduće performanse firme biti slabe, dok investitori ne mogu to da predvide. U ovom slučaju, menadžeri mogu kreirati odredbe upravljanja da bi zaštitili sebe od krivice ali odredbe ne doprinose uvek i isključivo stvaranju dodatnih agencijskih troškova.

Treće objašnjenje je da odredbe korporativnog upravljanja nemaju same po sebi neku moć, već su pre signal ili simptom viših agencijskih troškova - signal koji nije adekvatno inkorporisan u tržišne cene akcija korporacija.

Istraživanje na primeru srednjoevropskih i balkanskih zemalja zasnivalo se na proučavanju informacija o 24 različite odredbe korporativnog upravljanja za 150 firmi godišnje, u periodu od septembra 2000. godine do decembra 2005. godine. Pri konstrukciji Indeksa upravljanja autori su svakoj firmi, u kojoj postoji odredba koja ograničava prava akcionara, dodavali po jedan poen (što predstavlja povećanje moći menadžera). Prednost ovog Indeksa je njegova transparentnost i činjenica da se lako može ponovo izračunati, iako precizno ne izražava značaj i relativan uticaj pojedinih odredbi. Autori nisu, pri konstrukciji Indeksa, donosili zaključke o uticaju odredbi na bogatstvo akcionara ili efikasnost poslovanja, već su proučavali samo uticaj date odredbe na odnos snaga u korporaciji (akcionari-menadžeri).

Firme su uglavnom težile da prihvate što veći broj odredbi tokom devedesetih godina prošlog veka. Od ukupno 180 parova korelacija21 uspostavljenih između odredbi korporativnog upravljanja, 99 parova je pozitivno, od čega je 60 korelacija statistički značajno. Suprotno ovome, od 81 negativnih korelacija, samo je 20 korelacija statistički značajno. Ovo ukazuje da između firmi mogu postojati značajne razlike u raspodeli moći između akcionara i menadžera.

Uticaj pojedinih odredbi korporativnog upravljanja na efikasnost poslovanja i bogatstvo akcionara nije u potpunosti razjašnjen. Međutim, uprkos debati koja se u stranoj literaturi vodi o efektu otrovne pilule jasno je da otrovna pilula daje postojećem menadžmentu dodatnu moć da odoli kontrolnim akcijama velikih akcionara. Ukoliko mendžment razumno koristi ovu moć, bogatstvo korporacije će se povećavati. Ukoliko menadžment koristi otrovne pilule radi ostvarenja ličnih koristi, vrednost akcija korporacije bi se smanjila. Dakle, jasno je da otrovna pilula povećava moć menadžera i slabi kontrolna prava velikih akcionara. Ostale odredbe deluju na sličan način i, u skoro svim slučajevima, predstavljaju sredstvo kojim se menadžment odupire aktivizmu akcionara.

lako postojeće odredbe najčešće ukazuju na aktivnu ulogu menadžmenta i pokušaj da se ograniče prava akcionara, u slučaju dve odredbe postoji izuzetak: "tajno glasanje" i "kumulativno glasanje." Ove odredbe nastaju usled pritisaka akcionara. Tajno glasanje ili "glasanje o poverenju" u nekim firmama, zahteva imenovanje treće strane koja će brojati glasove zastupanja i podrazumeva zabranu menadžmentu da sazna kako je koji akcionar glasao. Kumulativno glasanje dozvoljava akcionarima da koncentrišu svoje glasove, tako da veliki broj manjinskih akcionara može obezbediti veći uticaj. Ove odredbe uglavnom zahtevaju akcionari uz mogućnost da ih menadžeri opozovu nakon predlaganja. Nasuprot tajnom i kumulativnom glasanju, nijedna od ostale 22 odredbe nema jasnu i snažnu podšku akcionara ili sigumu opoziciju menadžmenta. Odredbe tajnog i kumulativnog glasanja povećavaju prava akcionara. Zbog toga se, pri konstrukciji G za firmu u kojoj ne postoje ove odredbe, dodaje po jedan poen.

Kategorizacija za dve odredbe, zabrane zelene pošte i zlatni padobran, izgleda dvosmisleno. Zelena posta (greenmail) je situacija u kojoj potencijalni neprijateljski napadač preduzeća, koji je kupio većinski paket akcija, odustaje od preuzimanja prodajući paket akcija upravi preduzeća koje je bilo predmet preuzimanja po zelenaškoj, visokoj ceni. Akcije se otkupljuju od korporativnog napadača, po ceni koja je znatno viša od tekuće tržišne cene akcija korporacije, kako bi pretnja preuzimanja bila povučena. Postojanje ove odredbe obezbeduje dodatnu moć menadžmentu, kada je napadač akumulirao veliko učešće u akcijskom kapitalu. Dakle, odredba koja zabranjuje korišćenje zelene pošte smanjuje moć menadžera i povećava akcionarska prava. Međutim, zelena pošta je za napadače profitabilan posao, tako da bi zabrana zelene pošte učinila akumulaciju velikih "napadačkih" učešća manje profitabilnim, ex ante. Prisustvo zabrana zelene pošte je pozitivno korelisano sa 20 od 23 odredbe i, pored toga, značajno je pozitivno korelisano u osam odredbi, i nije značajno negativno korelisano ni sa jednom odredbom. Pošto su mnoge firme počele da koriste odredbu zelene pošte kao odbranu od preuzimanja, GIM zastupaju stanovište da odredbe zabrane zelene pošte smanjuju akcionarska prava. Zlatni padobran je klauzula u ugovoru o zaposlenju (koji potpisuju menadžeri) kojim se osigurava velika novčana isplata direktorima, odnosno članovima uprave, u slučaju prekida radnog odnosa ili premeštanja na drugi položaj u slučaju neprijateljskog preuzimanja preduzeća. To je zaštita top menadžera firme od neprijateljskih preuzimanja 
jer otpuštanje direktora čini vrlo skupim. lako bi ovakva plaćanja mogla da obeshrabre neprijateljsko preuzimanje jer povećavaju troškove neophodne za preuzimanje, ipak ne sprečavaju stvaranje merdžera. Dok je uticaj ove odredbe na poziciju menadžmenta i bogatstvo akcionara nejasan i dvosmislen, važniji efekat je smanjenje akcionarskih prava. U ovom slučaju, "pravo" je mogućnost kontrolnog akcionara da bez dodatnih troškova otpusti menadžment. Zlatni padobrani, kao i odredbe zabrane zelene pošte, su visoko korelisani sa svim ostalim odredbama odbrane od neprijateljskog preuzimanja. Od 23 parova korelacija sa drugim odredbama, ${ }^{19}$ su pozitivne, a 11 od ovih pozitivnih korelacija su statistički značajne, dok je samo jedna negativna korelacija statistički značajna. Prema tome, GIM posmatraju zlatne padobrane kao restrikciju prava akcionara.

Indeks upravljanja $(G)$ predstavlja zbir poena za svaku pojedinačnu odredbu (u slučaju postojanja ili odsustva svake odredbe) i rangira se od 0 do 24. GIM su vrednosti $G$ podelili u deset grupa koje se kreću od vrednosti $G<5$, zatim svaka pojedinačna vrednost za $G$ od $G=6$ do $G=13$, i završavaju se sa $\mathrm{G}>14$.

Izdvojena su dva ekstremna portfolija: menadžerski i akcionarski. Menadžerski portfolio (Management Portfolio) obuhvata firme sa najslabijom zaštitom vlasničkih prava (što odgovara najvišoj moći menadžera) i ima vrednosti G>14. To su firme koje imaju više od četmaest odredbi korporativnog upravljanja. Akcionarski portfolio (Shareholder Portfolio) obuhvata firme sa najjačom zaštitom vlasničkih prava (odgovara najslabijoj moći menadžera) i ima vrednosti $G<5$. Dakle, firme sa višim brojem indeksa (donji deo tabele) smeštene su u "Menadžment portfolio" a to znači da u njima postoji "najviša menadžerska moć" ili "najslabija akcionarska prava"; firme sa najnižom vrednošću indeksa (gomji deo Tabele 5) smeštene su u "akcionarski portfolio" što znači da imaju "najnižu moć menadžera" ili "najjača akcionarska prava."22

Tabela 1

Vrednosti koje može imati Indeks upravljanja (G)

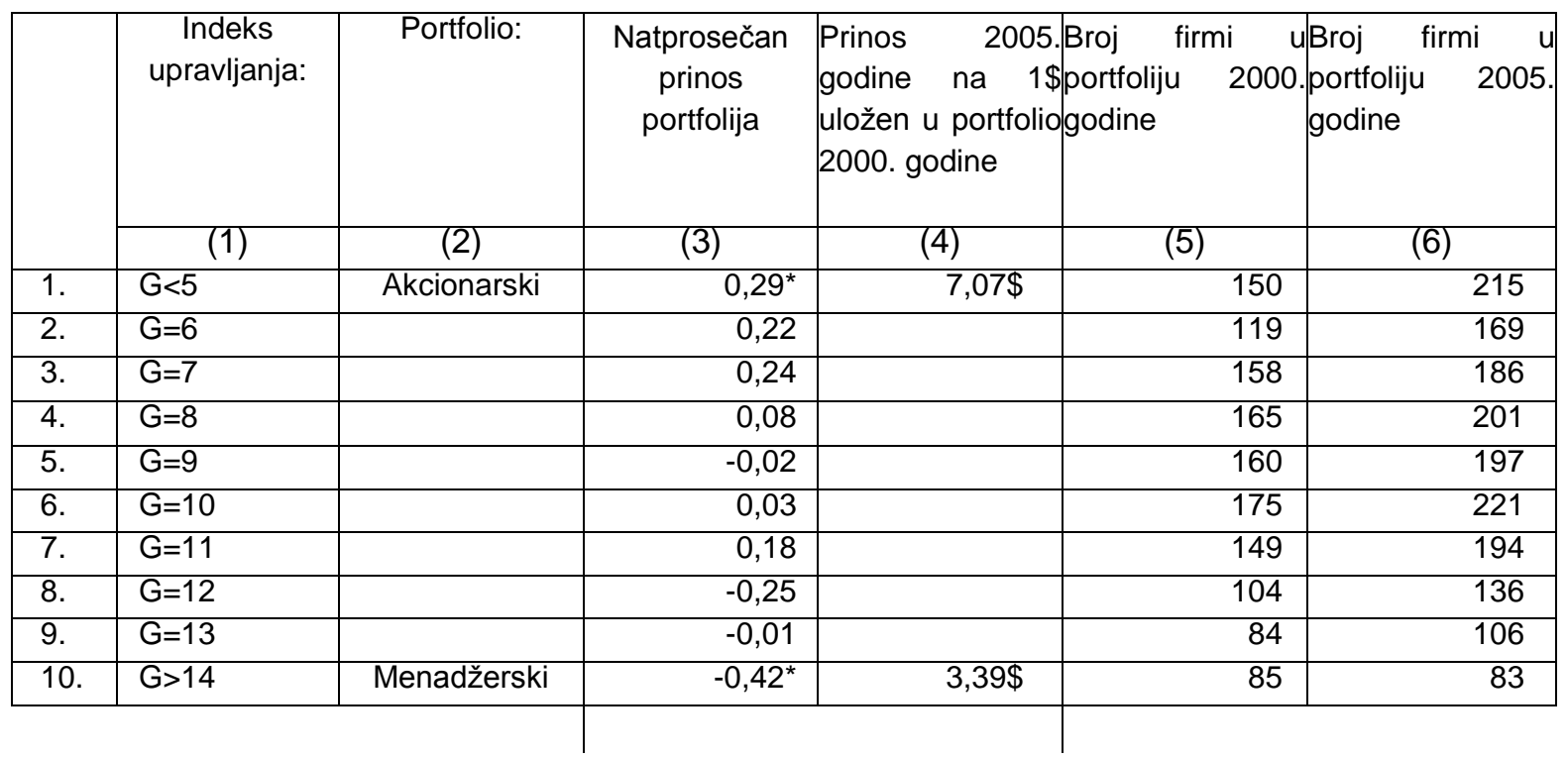

Kolona 1 prikazuje desetkarakterističnih vrednosti koje može imati G

Kolona 2 prikazuje dva ekstremna portfolija koja su predmet analize u istraživanju GIM.

Kolona 3 prikazuje natprosečan prinos koji može ostvariti portfolio koji sadrži akcije firmi deset različitih vrednosti G.

Kolona 4 prikazuje prinos koji bi bio ostvaren 2005. godine na $1 \$$ investicija u dva ekstremna portfolijau 2000. godini. Nivo značajnosti: ${ }^{*}=5 \%$

\footnotetext{
22 Uočeno da je od deset najvećih firmi u "Akcionarskom portfoliju" u 2000. godini, šest ostalo u akcionarskom portfoliju i u 2005. godini, tri su ispale iz portfolija i imaju $G=6$, i jedna je nestala iz primera. "Menadžerski portfolio" je bio aktivniji, sa samo dve od deset firmi sa najvećom tržišnom kapitalizacijom, koje su ostale u istom portfoliju, četiri firme su ispale iz portfolija sa $\mathrm{G}=13$ i tri firme su ispale iz uzorka posmatranja kroz merdžere ili emisiju dodatnih vrsta akcija (class of stock). Ukoliko se posmatra ceo uzorak firmi zapaža se da je od svih firmi, koje su bile u Akcionarskom i Menadžerskom portfoliju u 2000. godini, $31 \%$ i dalje ostalo u istom portfoliju u 2005. godini.
} 
Kolone 5 i 6 prikazuju broj firmi koje su bile obuhvaćene istraživanjem u 2000. i 2005. godini i vrednosti G koje su firme imale u godinama posmatranja.

\section{LITERATURA}

1. A. Paul Gompers, Joy L. Ishii, Andrew Metrick, Corporate Governance and Equity Prices, National Bureau of Economic Research Working Paper 8449, Cambridge, August, 2001.

2. E. Berglof, S. Claessens, Corporate Governance and Enforcement, World Bank Policy Research, Working Paper 3409, 2004, 5-27

3. S. Claessens, D. Simeon, F. Joseph, L. Larry, Expropriation of Minority Shareholders: Evidence from East Asia, World Bank, Working Paper No. 158, 1999, 46-73

4. A. Dyck, Privatization and Corporate Governance: Principles, Evidence and Future Challenges, Boston, Harvard Business School, 2000, 35

5. D. Dragojević, N. Vignjević-Đorđević, Menadžment i budžetska revizija u javnom sektoru, 12. međunarodni naučni simpozijum Symorg, Zlatibor, 2010, 86-97

6. D. Dragojević, N. Vignjević-Đorđević, Menadžment i budžetska revizija u javnom sektoru, Menadžment, Volume 2, 2010, 23-31

7. R. La Porta, F. Lopez-de-Silanes, A. Shleifer, R. Vishny, Law and Finance, National Bureau of Economic Research, Working paper 5661, 1996, 74-92

8. R. La Porta, F. Lopez-de-Silanes, A. Shleifer, R. Vishny, Investitor Protection: Origins, Consequences, Reform, National Bureau of Economic Research, Working paper 7428, 2003, 101123

9. R. La Porta, F. Lopez-de-Silanes, A. Shleifer, R. Vishny, Investitor Protection And Corporate Governance, Journal of Financial Economics No 58, 2006, 3-28,

10. L. Megginson, M. William, S. Netter, S. Chahyadi, Size and Impact of Privatisation - A Survey of Empirical Studies, Journal for Institutional Comparisons Volume 3, (1), 2006, 48-62

11. La Porta R., Lopez-de-Silanes F., Shleifer A., i R. Vishny, "Investor Protection and Corporate Govemance," Journal of Financial Economics 58, str. 3-28, 2000.

12. La Porta R., Lopez-de-Silanes F., Shleifer A., i R. Vishny, Investor Protection and Corporate Valuation, Harvard University, Working Paper, 2001.

13. K, Pistor, R. Martin, S. Gelfer, Law and Finance in Transition Economies, European Bank for Reconstruction and Development, Working paper No. 49, 2004, 171-213

14. E. Sheshinski, F. Lopez-Calva, Privatization and its Benefits: Theogu and Evidence, Harvard Institute for International Development Paper 698, 1999, 54-71

15. A. Shileifer, W. Vishny, A. Robert, Survey of Corporate Governance, National Bureau of Economic Research, Working Paper 5554, 1996, 37-63

16. J. Stiglitz, Information and The Change in The Paradigm in Economics, New York, Columbia Business School, 1997.

17. A. Shleifer, S. Johnson, Privatization and Corporate Governance, MIT and Harvard University, 2004.

18. N. Vignjević-Đorđević, Korporativno upravljanje i regulativa u funkciji razvoja javne svojine, konkurentnosti i transparentnosti tržišta, Kopaonik biznis forum - Rast u uslovima globalne recesije i finansijske krize: nekonvencionalne inicijative, Kopaonik, 2009, 235-246,

19. N. Vignjević-Đorđević, Korporativno upravljanje u osiguravajućim kompanijama i uticaj na lidersku poziciju, XVI naučni skup sa međunarodnim učešćem - Zemlje Zapadnog Balkana na putu ka EU, Palić, 2009, 13-18

20. N. Vignjević-Đorđević, Državna regulativa i korporativno upravljanje - makroekonomski aspekti konkurentnosti i transparentnosti finansijskog tržišta, Revizor br 51, 2010, 17-25

21. N. Vignjević-Đorđević, B. Radević, Javno upravljanje i kvalitet korporativnog upravljanjameđunarodna i domaća iskustva, Treća naučna konferencija Lemima, Novi Sad, 2011, 183-191

22. http://www.moodys.com/ i http://www.standardandpoors.com

\section{Abstract}

Corporate governance describes the agency problem resulting separation of ownership from control in modemoj corporation and represents a major expense for shareholders. The agency problem regulating legal protection of small shareholders, establishing the functions of the Supervisory Board of Directors as the body that controls the managers and active market for corporate control (hostile takeover). These mechanisms regulating the regulation of securities (at the federal level), corporate law (at state level), and corporate statutes, Contracting regulations and other rules (firm-level). These regulations, laws and regulations actually defining a distribution of power between shareholders and managers. Such techniques of takeover defense may be beneficial to shareholders, if managers are used to strengthen the bargaining power and increase the selling price of the company. However, if managers 
use to preserve their own positions and the achievement of personal interests, the provisions do not contribute to the realization of the interests of shareholders.

Key words: Corporate governance, equity, agency problem, shareholders, managers. 